\title{
Using the galvanostatic pulse method to estimate the corrosion of reinforcement in structural elements
}

\section{Uso del método del pulso galvanostático para estimar la corrosión de la armadura en elementos estructurales}

\author{
DOI: $10.46932 / \mathrm{sfjdv2n3-080}$
}

Received in: May 1st, 2021

Accepted in: Jun 30th, 2021

\author{
Wioletta Raczkiewicz \\ Kielce University of Technology \\ Ph.D \\ Kielce Al. Tysiąclecia P. P. 7, Poland, EU \\ E-mail: raczkiewicz.w@op.pl \\ Artur Wójcicki \\ Ph.D \\ Kielce University of Technology \\ Kielce Al. Tysiąclecia P. P. 7, Poland, EU \\ E-mail:wojcickia@wp.pl

\section{Adam Wójcicki} \\ M.Sc \\ E-mail: wojcicki-a@wp.pl
}

Kielce University of Technology, Kielce Al. Tysiąclecia P. P. 7, Poland, EU

\begin{abstract}
Early steel bars corrosion in reinforced concrete elements is difficult to detect because of the lack of visible changes on the concrete surface. To assess reinforcement corrosion risk level without structure damage some non-destructive diagnostic methods are applied. One of them is the galvanostatic pulse method. This semi-non-destructive electrochemical method allows to determine the corrosion areas and estimate the steel bars corrosion activity. Using this method it is possible to measure some electrical parameters (corrosion current density, stationary potential and reinforcement concrete cover resistivity) that allow to indirectly estimate the reinforcement corrosion progress in concrete. So far this method has been generally applied to bridges. The article presents results of studies in which the galvanostatic pulse method was used to determine reinforcement corrosion risk in structures elements different than bridges. Two types of reinforced concrete columns were tested under different environment conditions and two groups of laboratory specimens which were subjected to freezing and thawing cycles in $\mathrm{NaCl}$ solution or stayed in natural air-dry conditions. The apparatus GP-5000 GalvaPulse ${ }^{\mathrm{TM}}$ was used. Based on the obtained results the conclusions were drawn. The galvanostatic pulse method allows to assess the progress of the reinforcement corrosion process in tested elements. However, it is necessary to measure simultaneously all parameters and make their complex analysis.
\end{abstract}

Keywords: steel bar, reinforcement corrosion, non-destructive test method, laboratory test, filed test

\section{RESUMEN}

La corrosión temprana de las barras de acero en elementos de hormigón armado es difícil de detectar debido a la falta de cambios visibles en la superficie del hormigón. Para evaluar el nivel de riesgo de 
corrosión de la armadura sin dañar la estructura se aplican algunos métodos de diagnóstico no destructivos. Uno de ellos es el método del pulso galvanostático. Este método electroquímico semi no destructivo permite determinar las áreas de corrosión y estimar la actividad de corrosión de las barras de acero. Utilizando este método es posible medir algunos parámetros eléctricos (densidad de corriente de corrosión, potencial estacionario y resistividad de la cubierta del hormigón de la armadura) que permiten estimar indirectamente el progreso de la corrosión de la armadura en el hormigón. Hasta ahora este método se ha aplicado generalmente a los puentes. El artículo presenta los resultados de estudios en los que se utilizó el método de impulsos galvanostáticos para determinar el riesgo de corrosión de las armaduras en elementos de estructuras diferentes a los puentes. Se ensayaron dos tipos de columnas de hormigón armado en diferentes condiciones ambientales y dos grupos de probetas de laboratorio que se sometieron a ciclos de congelación y descongelación en solución de $\mathrm{NaCl}$ o permanecieron en condiciones naturales de secado al aire. Se utilizó el aparato GP-5000 GalvaPulseTM. A partir de los resultados obtenidos se extrajeron las siguientes conclusiones El método de impulsos galvanostáticos permite evaluar el progreso del proceso de corrosión de la armadura en los elementos ensayados. Sin embargo, es necesario medir simultáneamente todos los parámetros y realizar su complejo análisis.

Palabras clave: barra de acero, corrosión de la armadura, método de ensayo no destructivo, ensayo de laboratorio, ensayo archivado.

\section{INTRODUCTION}

Reinforced concrete elements used for many years under various conditions have different degree of destruction. Elements subjected to the direct weather impact and unprotected from it are subjected to the degradation faster than the others. The most dangerous are carbon dioxide from the air and dissolved in water chlorides. These factors, compounded by changes in temperature and humidity, as well as mechanical damage, lead to destruction of concrete cover and facilitate reinforcement corrosion (Fig. 1) [1-7].

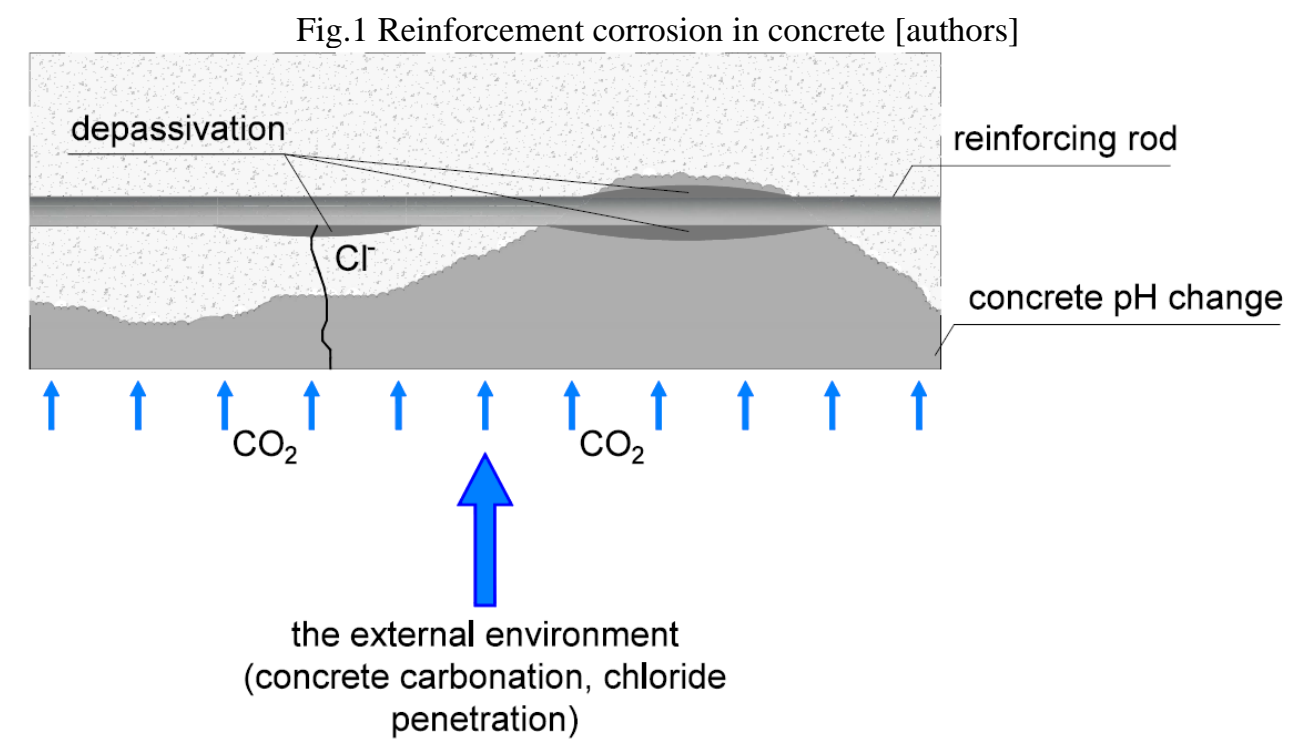

Because of the carbon dioxide and the physical - chemical processes effect the concrete carbonation appears. As a result of carbonation the concrete $\mathrm{pH}$ gradually decreases and the neutralized 
concrete areas reach deeper into the structure up to reaching the passive layer. At $\mathrm{pH}<\sim 11.8$ passive layer is destroyed and the electrochemical reinforcement corrosion can appear [1-4]. Sometimes, however, it may lead to the reinforcement corrosion development also at $\mathrm{pH}$ greater than 11.8. The most common reason of this type destruction are chlorides, which in the form of ions dissolved in the water penetrate the pores of the concrete structure and lead to local pitting [1-3]. In both cases: in the carbonation process or due to chloride penetration, external damage of concrete cover may be invisible while the reinforcement corrosion can be significant [1,5], as schematically is shown in Figure 1. On the other hand concrete cover may be damaged as a result of mechanical interactions. This type of damage is often visible but it doesn't mean that reinforcement corrodes [5,6]. Therefore the research methods that allow to determine the reinforcement corrosion risk in concrete elements without removal concrete cover are very significant $[8,9,10,11]$. One of these methods is non-destructive galvanostatic pulse method. So far this method has been generally applied to bridges $[5,10]$. The article presents results of studies in which this method was used to determine reinforcement corrosion risk in structures elements different than bridges. The main research objective was to assess the effectiveness of the measurements results made in various elements exposed to different environmental conditions defined according to the standard [12]. Therefore tests were performed on:

- laboratory specimens subjected to freezing cycles in the $3 \%$ sodium chloride solution (labeled F),

- laboratory specimens left in natural air - dry conditions (labeled $\mathrm{N}$ ),

- power poles (labeled P) that have been exposed to the real long-term impact of weather conditions $[6]$,

- internal columns of frame structure (labeled C) exploited under favorable environmental conditions.

\section{TEST METHOD}

Non-destructive electrochemical research methods were developed taking into account that the reinforcement corrosion process in concrete is an electrochemical process running in the electrolyte and the oxygen presence supply [2,9]. The electrolyte in this case is concrete with pores filled with an alkaline liquid and the reinforcing rod disposed is the electrode. On the rod's surface (due to micro defects in steel) local anode and cathode mini cells are produced, between which the rebar electrons flow, and the concrete is filled with the ions carrier liquid [2,8], as is schematically shown in Fig. 2. 
Fig. 2 Electrochemical corrosion process

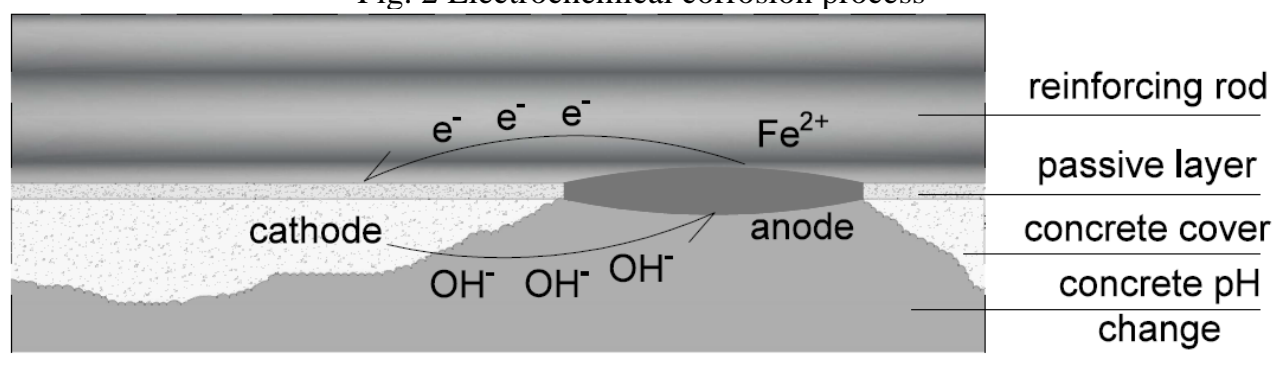

Using the galvanostatic pulse method it is possible to measure some electrical parameters $[8,10]$ that allow to estimate the reinforcement corrosion progress in concrete indirectly. The electrical parameters are: reinforcement stationary potential, concrete cover resistivity and the corrosion current density. The reinforcement stationary potential measurements and concrete cover resistivity are the basic measurements $[2,8]$, which allow only point out areas where conditions for corrosion are more favorable. These measurements are not very accurate $[6,13]$. More reliable are so-called advanced measurements [2,9], consisting of additional corrosion current density measurement so we can estimate the reinforcement corrosion activity and forecast its rate $[2,9,11]$.

One of the few devices which are designed for measuring the polarization is the GP-5000 GalvaPulse $^{\mathrm{TM}}$ set [11] using the galvanostatic pulse method. This set allows to perform basic or advanced measurements. The main set elements are: control and recording device (minicomputer Psion), silverchloride reference electrode and calibration device. The device GP-5000 GalvaPulse ${ }^{\mathrm{TM}}$ is designed for testing reinforced concrete structural elements [5,10,11]. Measurements are made on the surface points evenly distributed over the tested reinforcement what allows to create the graphical maps of measured parameters distribution and facilitates the results analysis. Before the measurements the reinforcement tested bar position should be determined, its continuity throughout the measuring section need to be checked and the concrete surface must be properly treated and strongly moisten using the spray method. During calibration the number and coordinates of the measuring points are declared on the tested surface as well as the pulse duration $(5 \div 20 \mathrm{~s})$ and the current intensity $(5 \div 400 \mu \mathrm{A}$; at the expected corrosion presence it is recommended the higher value), and rebar parameters (diameter), and also enable or disable the ring limiting the operating electrode influence. The apparatus is accompanied by information about the test results interpretation criteria (Table 1) [11]. Depending on the obtained stationary potential and reinforcement concrete cover resistivity values the reinforcement corrosion probability size in the studied area can be drawn, and on the corrosion current density basis the speed of the corrosion process can be estimated. 
Table 1 The criteria for assessing the reinforcement risk corrosion degree [11]

\begin{tabular}{|c|c|c|c|c|}
\hline \multicolumn{5}{|c|}{ Criteria for assessing the degree of reinforcement corrosion risk } \\
\hline \multirow{11}{*}{ 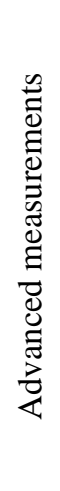 } & \multirow{6}{*}{$\begin{array}{c}\text { Basic } \\
\text { measurements }\end{array}$} & \multirow{3}{*}{$\begin{array}{l}\text { Reinforcement stationary } \\
\text { potential, } \mathrm{E}_{\mathrm{st}}[\mathrm{mV}]\end{array}$} & $>-200$ & $5 \%$ of corrosion probability \\
\hline & & & $-350 \div-200$ & $50 \%$ of corrosion probability \\
\hline & & & $<-350$ & $95 \%$ of corrosion probability \\
\hline & & \multirow{3}{*}{$\begin{array}{c}\text { Concrete cover resistivity, } \\
\qquad \Theta[\mathrm{k} \Omega \cdot \mathrm{cm}]\end{array}$} & $\geq 20$ & small corrosion probability \\
\hline & & & $10 \div 20$ & medium corrosion probability \\
\hline & & & $\leq 10$ & high corrosion probability \\
\hline & \multirow{5}{*}{\multicolumn{2}{|c|}{$\begin{array}{l}\text { Corrosion current density, } \\
\mathrm{i}_{\text {cor }}\left[\mu \mathrm{A} / \mathrm{cm}^{2}\right]\end{array}$}} & $<0,5$ & not forecasted corrosion activity \\
\hline & & & $0.5 \div 2.0$ & irrelevant activity corrosion \\
\hline & & & $2.0 \div 5.0$ & low corrosion activity \\
\hline & & & $5.0 \div 15.0$ & moderate corrosion activity \\
\hline & & & $>15.0$ & high corrosion activity \\
\hline
\end{tabular}

\section{LABORATORY AND FIELD TESTS}

The main aim of the research was to assess the effectiveness of the measurements results performed on the elements exposed to different environmental conditions.

\subsection{LABORATORY SPECIMENS RESEARCH}

There were 12 rectangular specimens with dimensions $210 \times 228 \times 100 \mathrm{~mm}$ made. All specimens were made according to a recipe for concrete class $\mathrm{C} 40 / 50$. There were following ingredients amounts per $1 \mathrm{~m}^{3}$ : cement (CEM I 52.5 ) - $390 \mathrm{~kg}$, sand $-660 \mathrm{~kg}$, gravel $2 \div 8-617 \mathrm{~kg}$, gravel $8 \div 16-694 \mathrm{~kg}$, water $155 \mathrm{l}$, plasticizer $(1.84 \mathrm{~g})$ and the aerator $(0.47 \mathrm{~g})$. As a reinforcement were used two parallel ribbed bars (BST 500) with a diameter of $8 \mathrm{~mm}$ placed in intervals $70 \mathrm{~mm}$ from the specimens edges side. The concrete cover was $25 \mathrm{~mm}$. All specimens were made in a laboratory with constant humidity and temperature (air-dry conditions).

The essential research to assess the reinforcement corrosion risk in the specimens was carried out in two stages. The first stage started 3 months after the specimens concreting. In all 12 specimens there were measurements made in accordance with the GP-5000 GalvaPulse ${ }^{\mathrm{TM}}$ set requirements [10]. For each specimen orthogonal grid of four measuring points was given (two points above each bar), where the stationary potential, concrete cover resistivity and corrosion current density were measured (Fig. 3). The results (which were reference values for the later measurements) have been stored in the database. Afterwards specimens were divided into two groups: group A (6 pieces, Numbers F1 $\div$ F6; specimens which were subjected to 120 freezing and thawing cycles in $3 \%$ sodium chloride $(\mathrm{NaCl})$ in order to initiate chloride corrosion on the reinforcement), group B (6 pieces, Numbers $\mathrm{N} 1 \div \mathrm{N} 6$; specimens left in natural laboratory air-dry conditions). 
Fig. 3 Photograph of the measurements on one sample

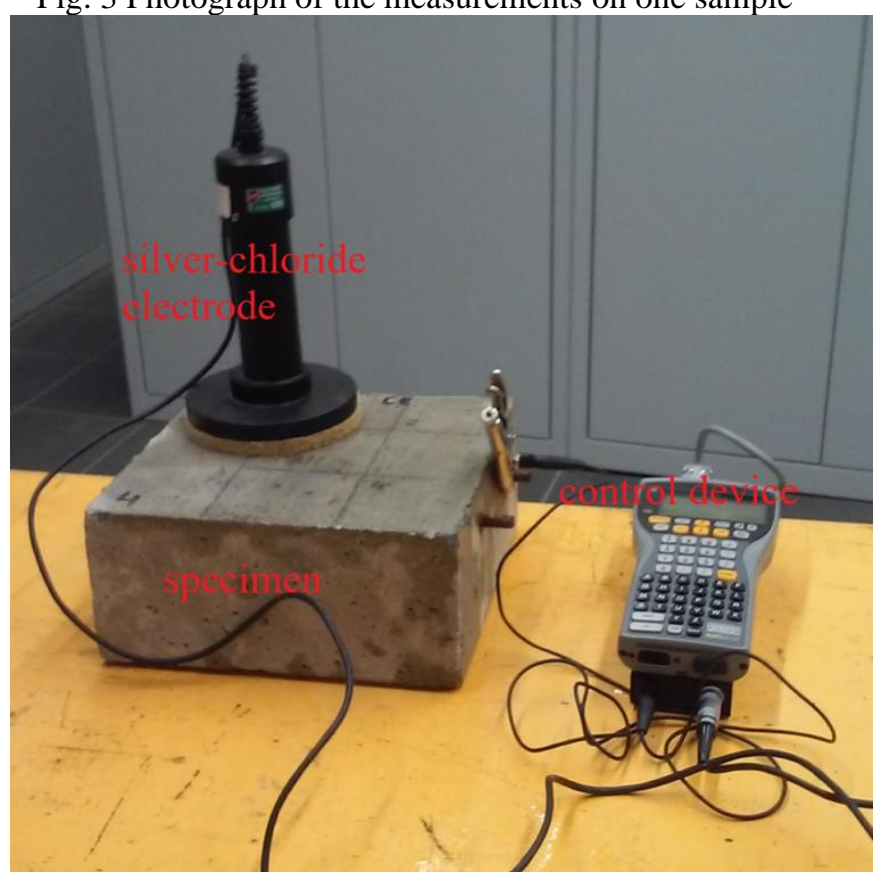

Analogous measurements were performed on specimens N1 $\div$ N6 kept in air-dry conditions. Obtained results (Tables $2.1 \div 2.3$ ) were analyzed on the criteria given in Table 1 [11].

Table 2.1 The corrosion current density measurement results

\begin{tabular}{|c|c|c|c|c|c|c|c|c|c|}
\hline \multirow{3}{*}{\multicolumn{2}{|c|}{ Specimen $\mathrm{N}^{\mathrm{o}}$}} & \multicolumn{8}{|c|}{ corrosion current density, $\mathrm{i}_{\text {cor }}\left[\mu \mathrm{A} / \mathrm{cm}^{2}\right]$} \\
\hline & & \multicolumn{4}{|c|}{ stage I (initial measurements) } & \multicolumn{4}{|c|}{ stage II } \\
\hline & & point 1 & point 2 & point 3 & point 4 & point 1 & point 2 & point 3 & point 4 \\
\hline \multirow[t]{6}{*}{ group A } & $\mathrm{F} 1$ & 1.08 & 1.07 & 1.25 & 1.19 & 4.27 & 4.22 & 4.86 & 3.63 \\
\hline & F2 & 1.74 & 1.17 & 1.48 & 0.96 & 6.37 & 6.59 & 6.12 & 6.37 \\
\hline & F3 & 1.31 & 1.16 & 1.20 & 0.98 & 6.78 & 5.01 & 6.54 & 4.90 \\
\hline & F4 & 1.15 & 1.05 & 1.00 & 1.07 & 5.46 & 6.08 & 2.60 & 2.54 \\
\hline & F5 & 1.04 & 1.08 & 0.86 & 1.24 & 6.23 & 4.87 & 4.98 & 5.10 \\
\hline & F6 & 1.07 & 0.95 & 1.12 & 1.18 & 7.93 & 6.07 & 3.96 & 3.56 \\
\hline \multirow[t]{6}{*}{ group B } & N1 & 0.63 & 0.58 & 0.64 & 0.62 & 0.36 & 0.25 & 0.46 & 0.29 \\
\hline & $\mathrm{N} 2$ & 0.77 & 0.83 & 0.73 & 0.99 & 0.38 & 1.11 & 0.37 & 0.51 \\
\hline & N3 & 1.29 & 1.36 & 1.12 & 1.29 & 0.41 & 0.31 & 0.44 & 0.35 \\
\hline & N4 & 0.92 & 1.01 & 1.03 & 0.99 & 0.44 & 0.39 & 0.42 & 0.55 \\
\hline & N5 & 1.51 & 1.02 & 1.15 & 1.02 & 0.74 & 0.60 & 0.53 & 0.57 \\
\hline & N6 & 1.63 & 1.07 & 1.38 & 1.02 & 0.59 & 0.59 & 0.48 & 0.43 \\
\hline
\end{tabular}


Table 2.2 The reinforcement stationary potential measurements results

\begin{tabular}{|c|c|c|c|c|c|c|c|c|c|}
\hline \multirow{3}{*}{\multicolumn{2}{|c|}{ Specimen $\mathrm{N}^{\circ}$}} & \multicolumn{8}{|c|}{ reinforcement stationary potential, $\mathrm{E}_{\mathrm{st}}[\mathrm{mV}]$} \\
\hline & & \multicolumn{4}{|c|}{ stage I (initial measurements) } & \multicolumn{4}{|c|}{ stage II } \\
\hline & & point 1 & point 2 & point 3 & point 4 & point 1 & point 2 & point 3 & point 4 \\
\hline \multirow[t]{6}{*}{ group A } & F1 & -230 & -217 & -226 & -223 & -218 & -232 & -141 & -203 \\
\hline & $\mathrm{F} 2$ & -178 & -210 & -201 & -214 & -189 & -203 & -253 & -188 \\
\hline & F3 & -228 & -319 & -224 & -239 & -299 & -295 & -221 & -320 \\
\hline & F4 & -168 & -275 & -165 & -262 & -220 & -221 & -224 & -212 \\
\hline & F5 & -150 & -156 & -257 & -249 & -282 & -341 & -288 & -335 \\
\hline & F6 & -174 & -246 & -180 & -247 & -271 & -254 & -266 & -252 \\
\hline \multirow[t]{6}{*}{ group B } & $\mathrm{N} 1$ & -35 & -31 & -34 & -17 & -84 & -55 & -120 & -69 \\
\hline & N2 & -51 & -63 & -262 & -263 & -10 & 9 & -123 & -94 \\
\hline & $\mathrm{N} 3$ & -217 & -224 & -326 & -327 & -109 & -67 & -132 & -92 \\
\hline & $\mathrm{N} 4$ & -123 & -121 & -234 & -225 & -128 & -125 & 69 & 70 \\
\hline & $\mathrm{N} 5$ & -166 & -172 & -221 & -209 & -125 & -123 & -124 & 78 \\
\hline & N6 & -199 & -256 & -213 & -259 & -116 & -130 & -180 & -220 \\
\hline
\end{tabular}

Table 2.3 The concrete cover resistivity measurements

\begin{tabular}{|c|c|c|c|c|c|c|c|c|c|}
\hline \multirow{3}{*}{\multicolumn{2}{|c|}{ Specimen $\mathrm{N}^{\mathrm{o}}$}} & \multicolumn{8}{|c|}{ concrete cover resistivity, $\Theta[\mathrm{k} \Omega \cdot \mathrm{cm}]$} \\
\hline & & \multicolumn{4}{|c|}{ stage I (initial measurements) } & \multicolumn{4}{|c|}{ stage II } \\
\hline & & point 1 & point 2 & point 3 & point 4 & point 1 & point 2 & point 3 & point 4 \\
\hline \multirow{6}{*}{ group A } & F1 & 1.2 & 1.2 & 1.1 & 1.1 & 1.9 & 1.8 & 1.8 & 2.4 \\
\hline & $\mathrm{F} 2$ & 1.2 & 1.3 & 1.2 & 1.3 & 1.3 & 1.4 & 1.4 & 1.5 \\
\hline & F3 & 1.4 & 1.4 & 1.3 & 1.2 & 1.5 & 1.4 & 1.6 & 1.7 \\
\hline & F4 & 1.3 & 1.2 & 1.2 & 1.2 & 1.0 & 1.2 & 1.0 & 1.3 \\
\hline & F5 & 1.3 & 1.2 & 1.3 & 1.2 & 1.1 & 1.1 & 1.0 & 1.2 \\
\hline & F6 & 1.3 & 1.2 & 1.2 & 1.2 & 1.0 & 1.2 & 1.1 & 1.2 \\
\hline \multirow{6}{*}{ group B } & N1 & 1.4 & 1.5 & 1.5 & 1.4 & 26.5 & 22.2 & 29.2 & 27.2 \\
\hline & $\mathrm{N} 2$ & 1.4 & 1.2 & 1.3 & 1.3 & 34.0 & 24.9 & 18.2 & 16.2 \\
\hline & N3 & 1.3 & 1.3 & 1.2 & 1.1 & 28.2 & 23.2 & 23.9 & 22.8 \\
\hline & N4 & 1.4 & 1.3 & 1.3 & 1.2 & 22.1 & 26.3 & 22.1 & 28.3 \\
\hline & N5 & 1.2 & 1.2 & 1.3 & 1.2 & 24.7 & 23.7 & 26.6 & 28.9 \\
\hline & N6 & 1.3 & 1.3 & 1.2 & 1.1 & 26.2 & 26.1 & 23.5 & 25.4 \\
\hline
\end{tabular}

\subsection{RESEARCH OF POLES}

Two types of reinforced concrete poles were tested. The first poles type were exterior poles (labeled P). They were exposed to long-term environmental impact, including in particular the negative atmospheric conditions impact (Fig. 4a). Poles were reinforced with ribbed bars with a $8 \mathrm{~mm}$ diameter. The concrete cover was $8 \div 10 \mathrm{~mm}$. Three poles were examined. These elements' the average concrete strength was measured by rebound hammer test and was $\sim 37 \mathrm{MPa}$. The age of poles was estimated at 50 years.

The second poles type were reinforced concrete load bearing internal columns (labeled C) (Fig. 4b). The columns' reinforcement was made of ribbed bars with a $20 \mathrm{~mm}$ diameter. The concrete cover was $20 \div 25 \mathrm{~mm}$. The four columns were subjected to the study. The average concrete pillars strength made by the rebound hammer test was $55 \mathrm{MPa}$. The age of columns was estimated at $\sim 48$ years. 
Fig. 4. a) Twin power pole - P; b) Column of load-bearing structure in the building - C

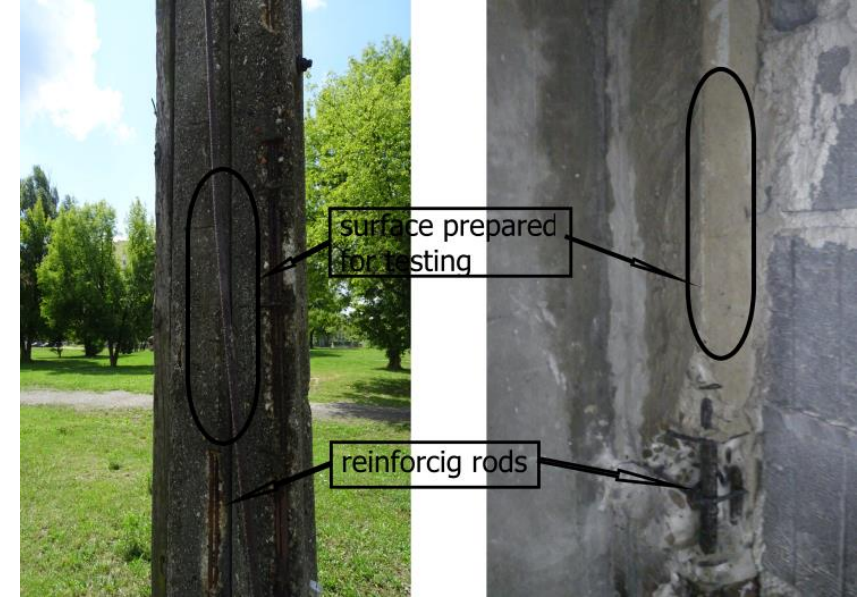

(a)

(b)

Electrochemical studies involved the reinforcement stationary potential, concrete cover resistivity and corrosion current density measurements at three measuring points located directly above the main reinforcement and spaced every $30 \mathrm{~cm}$. The research on the rod was made during the summer - the dry season when the ambient temperature was $\sim 27^{\circ} \mathrm{C}$. Research on poles was made in the building during the autumn when temperatures inside the building was around $3{ }^{\circ} \mathrm{C}$. All measurements were recorded (Table 3 ) and analyzed on the criteria given in Table $1[6,11]$.

Table 3 The power poles and poles of the building structure measurements results

\begin{tabular}{|c|c|c|c|c|c|c|c|c|c|}
\hline \multirow[t]{2}{*}{$\begin{array}{l}\text { Pole } \\
\mathrm{N}^{\mathrm{o}}\end{array}$} & \multicolumn{3}{|c|}{$\begin{array}{l}\text { corrosion current density, } \\
\mathrm{i}_{\mathrm{cor}}\left[\mu \mathrm{A} / \mathrm{cm}^{2}\right]\end{array}$} & \multicolumn{3}{|c|}{$\begin{array}{l}\text { reinforcement stationary potential, } \\
\qquad E_{\mathrm{st}}[\mathrm{mV}]\end{array}$} & \multicolumn{3}{|c|}{$\begin{array}{c}\text { concrete cover resistivity, } \\
\Theta[\mathrm{k} \Omega \cdot \mathrm{cm}]\end{array}$} \\
\hline & point 1 & point 2 & point 3 & point 1 & point 2 & point 3 & point 1 & point 2 & point 3 \\
\hline P 1a & 2.25 & 2.99 & 5.7 & -36 & 29 & -86 & 6.1 & 10.5 & 13.9 \\
\hline $\mathrm{P} 1 \mathrm{~b}$ & 1.76 & 21.76 & 4.6 & -41 & -81 & -72 & 8.2 & 14.1 & 13.5 \\
\hline $\mathrm{P} 2 \mathrm{a}$ & 1.63 & 1.2 & 0.71 & -47 & -30 & -9 & 5.8 & 5.0 & 7.7 \\
\hline $\mathrm{P} 2 \mathrm{~b}$ & 1.95 & 1.47 & 1.49 & -7 & -10 & -10 & 3.7 & 6.4 & 5.4 \\
\hline P 3a & 1.61 & 0.94 & 1.06 & -61 & -4 & -29 & 5.8 & 7.7 & 6.3 \\
\hline P 3b & 1.25 & 1.31 & 0.60 & -27 & -33 & -15 & 6.0 & 4.7 & 4.0 \\
\hline P 3c & 1.66 & 1.26 & 0.38 & -54 & -47 & -1 & 5.4 & 4.8 & 4.0 \\
\hline C 1a & 0.05 & 0.05 & 0.04 & -141 & -96 & -108 & $63^{*}$ & $60^{*}$ & $55^{*}$ \\
\hline $\mathrm{C} 1 \mathrm{~b}$ & 0.09 & 0.11 & 0.10 & 1.87 & -89 & -97 & 26.5 & 31 & 21.5 \\
\hline C 2 & 0.13 & 0.07 & 0.08 & -126 & 1.6 & -115 & 34.6 & 15.6 & 26.2 \\
\hline C 3 & 0.10 & 0.05 & 0.07 & -134 & -81 & -85 & 8.9 & 20.2 & 23.6 \\
\hline $\mathrm{C} 4$ & 0.00 & 0.42 & 0.04 & -144 & -49 & -99 & 9.9 & 24.7 & 28.9 \\
\hline
\end{tabular}

* results out of the test range [10]

\section{ANALYSIS OF THE RESULTS}

\subsection{LABORATORY SPECIMENS}

The main parameter by which we can determine the reinforcement corrosion progress is corrosion current density measurement. Other parameters, for advanced research, are less important -specify only 
circumstances which can lead to the reinforcement corrosion. Corrosion current density measurement made in the research first stage on all 12 specimens indicated that at no measuring point the corrosion current density exceed $\mathrm{i}_{\mathrm{cor}}=2 \mu \mathrm{A} / \mathrm{cm}^{2}$ which, according to adopted criteria (Table 1) shows negligible corrosion activity. The obtained results comparison in the study second stage showed that at the measuring points of the specimens $\mathrm{A}$ (subjected to freezing cycles in a $3 \% \mathrm{NaCl}$ solution) the corrosion current density at 11 points increased significantly reaching $\mathrm{i}_{\text {cor }}=2.54 \div 4.98 \mu \mathrm{A} / \mathrm{cm}^{2}$, providing low-activity, and at 13 points $\mathrm{i}_{\text {cor }}=5.00 \div 7.93 \mu \mathrm{A} / \mathrm{cm}^{2}$, with a moderate corrosion activity. The specimens of group $\mathrm{B}$ (stored under natural dry - air conditions) the corrosion current density measurement in the second stage do not appear to alter the reinforcement corrosion activity - the value of the parameter measurements in both stages remained the same level and do not exceed $2 \mu \mathrm{A} / \mathrm{cm}^{2}$ (Table 2.1). The reinforcement stationary potential measurements results did not allow for the clear conclusions (Table 2.2). In the first measurements stage (performed on three-month-old specimens) at the 30 measurement points of twelve specimens the reinforcement stationary potential was lower than $-200 \mathrm{mV},\left(\mathrm{E}_{\mathrm{st}}=-201 \div-327 \mathrm{mV}\right)$ which, in accordance with Table 1, indicated 50\% of reinforcement corrosion probability. Only at 18 measurement points, these values were higher than $-200 \mathrm{mV}$ allowing to estimate the corrosion probability at the level of $5 \%$. In the measurements second stage at 17 points of specimens A (subjected to freezing cycles in $3 \% \mathrm{NaCl}$ solution) the reinforcement stationary potential decreased in relation to the measurement in the first stage where in the reinforcement corrosion probability increase may be requested, although the results indicated that it was still at 50\%. In seven measuring points potential value increased. In three-point value was greater than $-200 \mathrm{mV}$, indicating low than $5 \%$ corrosion probability. In all measuring points of the specimens group B (which are kept in air - dry conditions) in a second stage measuring the reinforcement stationary potential values were higher than $-200 \mathrm{mV}$, which indicate the corrosion probability at $5 \%$ level. Compared to the measurements made in the first stage at 13 measuring points the corrosion probability was reduced from $50 \%$ to $5 \%$. The concrete cover resistivity measured values in the first stage at all twelve points of the specimens ranged $\Theta=1.1 \div 1.5 \mathrm{k} \Omega \cdot \mathrm{cm}$ (Table 2.3). It was much less than $10 \mathrm{k} \Omega$ and indicated a high corrosion probability (Table 1). In a second measuring stage at the measuring points of the samples A (subjected to freezing cycles in $3 \% \mathrm{NaCl}$ solution) the parameter value still remained at the same level $(\Theta=1.0 \div 2.4 \mathrm{k} \Omega \cdot \mathrm{cm})$. However, in the specimens of group B (which are kept in air - dry conditions) at 22 measurement points the concrete cover resistivity increased over $20 \mathrm{k} \Omega \cdot \mathrm{cm}$, allowing to estimate the corrosion probability as low (Table 2.3 ). 


\subsection{POLES AND COLUMNS}

As noted in section 3.2, before described research the poles have been operated for about 50 years. The study involved power poles (elements with visible damage, exposed to the long-term adverse weather conditions effects, conducive to corrosion) and the columns of load bearing structure in the building of an earlier repair stage after years of operation (when operating elements are well protected from external influences and moisture). This element groups choice allowed to compare the results of reinforcement corrosion elements threat operated in extremely different conditions and at the same time unambiguous, sensory and macroscopic evaluation. The testing poles results are described above in Table 3 . They were analyzed based on the same criteria as the specimens [10]. According to the given in [10] nomenclature of corrosion current density obtained from measurements on power poles (results range $\mathrm{i}_{\text {cor }}=0.38 \div 21.76$ $\mu \mathrm{A} / \mathrm{cm}^{2}$ ) indicated a "high corrosion activity" of reinforcement in the P1b pole (at one point $\mathrm{i}_{\text {cor }}=21.76$ $\mu \mathrm{A} / \mathrm{cm}^{2}$ ), "moderate" in the P1a pole (at one point $\mathrm{i}_{\mathrm{cor}}=5.7 \mu \mathrm{A} / \mathrm{cm}^{2}$ ), and the remaining poles at "insignificant corrosion activity". The same parameter allowed to determine the reinforcement corrosion activity in the frame columns $(\mathrm{C} 1 \div \mathrm{C} 4)$ as "not forecasted" (results range $\mathrm{i}_{\text {cor }}=0 \div 0.42 \mu \mathrm{A} / \mathrm{cm}^{2}$ ). On the measurements basis of the second parameter, i.e. the reinforcement stationary potential the corrosion likelihood can be drawn about at $5 \%$ in both types of poles. The value ranges results were similar and were as follows: for power poles $\mathrm{E}_{\mathrm{st}}=-86 \div 29 \mathrm{mV}$, and for columns $\mathrm{E}_{\mathrm{st}}=-144 \div 1.87 \mathrm{mV}$. It should be noted that this parameter does not show precisely observed, in fact, the existing differences in the reinforcement wear degree or both types corrosive poles threats (visible reinforcement of poles places were clearly corroded). The third measured value, concrete cover resistivity, allowed for clearer (but also imprecise) determination of the reinforcement rod condition difference undergoing long-term impact of unfavorable external conditions and poles operated under favorable conditions. The results values for power poles ranged $\Theta=3.7 \div 14.1 \mathrm{k} \Omega \cdot \mathrm{cm}$ clearly indicated a "medium" (four points) and "high corrosion probability" (most points) of reinforcing bars. The obtained results for columns ranged $\Theta=$ $20.2 \div 34.6 \mathrm{k} \Omega \cdot \mathrm{cm}$ indicating a "low corrosion probability" (most points) and range $\Theta=9.9 \div 15.6 \mathrm{k} \Omega \cdot \mathrm{cm}$, providing a "medium corrosion probability" (three points).

\section{CONCLUSIONS}

1. The galvanostatic pulse method allows to assess the progress of the reinforcement corrosion process in both laboratory specimens and the real elements. However, it is necessary to measure simultaneously all three parameters (corrosion current density, stationary potential and reinforcement concrete cover resistivity) and make their complex analysis. 
2. Only basic measurements performance (reinforcement stationary potential and concrete cover resistivity) can lead to wrong conclusions.

3. Among the three measured values the corrosion current density is the most reliable measurement.

4. Concrete cover resistivity measurement made on new specimen is not reliable (indicates high reinforcement corrosion probability). This may be related to the physicochemical changes, occurring in young concrete due to the strong surface moisture during the measurements.

5. The reinforcement stationary potential measurement made on new specimens indicates high $-50 \%$ corrosion probability and in the 50 years old poles $5 \%$ corrosion probability what proves the inaccurate results.

6. Measurement performance is only possible on a leveled, carefully purified and strongly moisturized concrete surface.

7. The ambient temperature during the measurements can affect the obtained results both for the test piece (heating or strong cooling and even freeze) and because of the measuring apparatus behavior. Preliminary measurements made on the same laboratory specimens outdoors in the winter (temp. $5^{\circ} \mathrm{C}$ ) and, immediately after it, in a warm room (temp. $\sim 23^{\circ} \mathrm{C}$ ) showed repeatable and significant differences in the values of all three measured parameters: corrosion current density, the reinforcement stationary potential and the concrete cover resistivity. This research is being continued by authors. 


\section{REFERENCES}

[1] Tang S.W., Yao Y., Andrade C., Li Z.J.: Recent durability studies on concrete structure, Cement and Concrete Research, 78 (part A)/2015, pp 143-154

[2] Zybura A., Jaśniok M., Jaśniok T.: Diagnostics of reinforced concrete structures. Corrosion of reinforcement and protective properties of concrete, PWN, Warsaw 2011

[3] Verma S.K., Bhadauria S.S., Akhtar S.: Monitoring Corrosion of Steel Bars in Reinforced Concrete Structures, The Scientific World Journal, 2014

[4] Bertolini L, Elsener B, Pedeferri P, Polder R: Corrosion of steel in concrete, WILEY VCH, Weinheim, 2004

[5] Łakomy T.: Corrosion of the reinforcement bridges depend on the concrete structure. Doctoral thesis, WIL PW, Warsaw 2009

[6] Raczkiewicz W., Wójcicki A.: The reinforcement elements corrosion threat of the reinforced concrete operated long-term in extremely different exposure conditions, XX Conference of Science and Technology Kontra 2016, Construction Review 5/2016, pp 45-47

[7] Sardjito, Nani Yuningsih: Determination of Object Temperature Influenced by Ambient Temperature as a Solution of Newton's Law of Cooling or Heating Rates, South Florida Journal of Development, Miami, v.2, n.3, p.4563-4573special edition, jul. 2021.ISSN DOI: 10.46932/sfjdv2n3-058

[8] Song H-W., Saraswathy V.: Corrosion monitoring of reinforced concrete structures - A review. International Journal of Electrochemical Science 2/2007, pp 1-28

[9] Raczkiewicz W.: Non-destructive methods of risk assessment corrosion of reinforcing steel in concrete, monograph: Various aspects of the quality of the materials and processes used in construction, Kielce University of Technology Publishing House, M70/2015, pp 9-22

[10] Elsner B. et al: Assessment of reinforcement corrosion by means of galvanostatic pulse technique, Proceedings, International Conference "Repair of Concrete Structures”, Svolvaer, Norway, 1997

[11] http://www.germann.org/TestSystems/GalvaPulse/GalvaPulse.pdf

[12] EN 1992-1-1: 2008 Eurocode 2. Design of concrete structures. Part 1-1: General standard and standards for buildings

[13] Kuźniak J., Woyciechowski P., Wcisło A.: The chloride content in cement steel with protective abilities of the reinforcement concrete cover Corrosion protection 6/2016, pp 196-199 